\title{
Design and Development of a Safety Educational Adventure Game
}

\author{
https://doi.org/10.3991/ijet.v14i03.9268 \\ Feng-Kuang Chiang $\left({ }^{\square}\right)$ \\ Shanghai Normal University, Shanghai, China \\ fkchiangeshnu.edu.cn \\ Chun-Hao Chang \\ National Taiwan Normal University, Taipei, Taiwan \\ Danni Hu, Geran Zhang, Ying Liu \\ Beijing Normal University, Beijing, China
}

\begin{abstract}
The lack of effective safety education training in curriculum design could expose children to serious safety accidents both in schools and at homes. To highlight the importance of safety education, we intended to design and implement an adventure video game (AVG) on mobile devices, hoping to improve children's safety knowledge and skills through interactive gameplay. The proposed AVG app situated children in real dangerous circumstances through roleplaying and then engaged them in learning safety related knowledge through case scenarios. To balance the entertainment and edutainment of the game, this app integrated theories of game design and child development to support its design rationale, including interface interaction and game badges. This app was evaluated through interviews and video analysis so that later improvements were made according to feedback from participants, parents and experts.
\end{abstract}

Keywords-Adventure video game, children safety education, mobile gamebased learning, application design; game badge

\section{Introduction}

It is commonly believed that one's safety isn't expensive; instead, it's priceless. Understanding the fundamentals of safety knowledge is critical to children's everyday life. Although the Chinese government as well as international society has placed great emphasis on the importance of children's life safety, the occurrence of safety accidents is still the number one cause of death among children under 9, snatching away more than 10 thousand of lives each year in China. For instance, electrical hazards could result in significant safety issues to children yet they may not have sufficient knowledge about the safe use of electricity. Similarly, road injuries remain a serious public safety threat for Australian children as it continues to be one of the leading causes of death for children under the age of 5 [1]. 
However, safety education carried out by schools and families can hardly achieve the desired results due to some defects such as low frequency of drills for practice, difficulties in class infiltrate and a shortage of safety education resources $[2,3]$. Besides, in conventional classroom settings, teachers tend to focus more on safety related factual knowledge rather than operational skills, more on prevention announcements rather than coping measures, more on escape strategies rather than rescue practices. In addition, classroom instructions are often in the form whole group lecture, making it difficult for teachers to provide instructional supports according to individual needs. To make matters worse, parents are likely not in the loop for safety education learning issues. They are neither unaware of nor pay little attention to the importance of safety education issues [4]. Yet, it was found that parents' active participation and involvement can significantly increase a child's learning results of safety education [5]. Therefore, it seems the design and implementation of teaching children safety related knowledge pivots heavily upon the collaboration among teachers, children and parents.

Despite unavoidably flawed traditional forms of safety education, in recent years, the integration of learning technologies into learning sheds light on the instructional design of safety education. In particular, edutainment or serious games have attracted an increased number of researchers' sight, which may be able to make up for the deficiencies of traditional forms. Though review of the literature reveals that a few researchers have already developed video games related to teach certain aspects of safety education, there are still a few disputable points in previous studies to be solved. First, previous safety education games laid particular stress on demonstrating safety principles while the design of various situations, interactive feedback or reward system was often ignored. Second, the design of safety games tended to loose balance between its educational implications and entertaining features. For instance, Dumb Ways to Die is a representative case by presenting unpractical operations in dangerous situations that are entertaining enough to hide the game's educational function. Lastly, in terms of assessment, previous records of development process usually involve little information about methods and results of survey, making the actual effect and causal relationships unknown.

To this regard, this study proposed the use of an adventure video game (AVG) when acquainting children with safety related learning issues. It is notable that story line plays a prominent and defining role in AVGs. Players are often placed in a firstperson perspective when dealing with a problem throughout various scenes in the game [6]. At the same time, mobile learning is becoming an indispensable part of basic learning for its portability, openness, high efficiency, etc. Therefore, this article is going to make an attempt by turning to mobile learning and game-based learning to find a more convenient and efficient way of safety education. Combining AVG with safety education allows children to experience the real dangerous situations as the story progresses. The purpose of this study is to find and test a strategy unifying education with entertainment, to provide new resources for safety education in schools and families and to increase children's life safety awareness of children, parents and teachers by the game. 


\section{Relevant Literature}

\subsection{Safety education for young children}

Childhood safety is always an important educational issue. Safety education generally refers to the teaching of specific knowledge and skills that children need to learn in order to stay safe or live safely in a presented situation. The goal of teaching usually focuses on enabling children to recognize the potential dangers of the learning subject or the possible hazards posed by the learning subject [7]. Though the study of safety related knowledge is considered as an imminent skill set for children to acquire in order to protect themselves, the learning and teaching of safety education doesn't receive as much educational attentions as other academic domains such as the STEM education. In fact, teaching children safety knowledge is not an easy task because safety education encompasses a wide spectrum of learning issues. In practice, teaching children safety knowledge often centers around topics such as road safety, personal safety, food safety and electricity safety that are closely intertwined with children's everyday life [8]. From previous classroom experiences and empirical study findings, we have identified and summarized five major educational issues to be coped with when guiding children to learn safety knowledge in lectured-based classroom settings.

The lack of a situated learning context: Conventional lecture-based instruction lacks to create a tangible, situated learning context for children to reflect on or construct their mental models about the safety knowledge. Thus, it becomes challenging for children to foresee the need to learn safety knowledge or assimilate the knowledge imparted by the instructor. From theoretical viewpoints, it was asserted that knowledge needed to be presented in authentic contexts and situations that would normally involve the use of that knowledge [9]. Children would become more inclined to learn safety knowledge if the learning context is scenario-based and conducive to their active participation in the learning experience.

Disconnections between personal experiences and safety knowledge: Lectures, practices and home assignments do not necessarily translate into a child's full understanding of safety knowledge. Instead, effective learning requires a mechanism that can stimulate a child's reflections of personal experiences about relevant real world context. However, conventional teaching approach of safety education fails to tailor to personal experiences or operational skills that are essential to the mastery of safety knowledge. It was found that children absorb new knowledge more efficiently when they bring in relevant experiences in the past because such experiences can foster deeper thinking and reflection concerning the subject they are learning $[10,11]$. One's personal experiences are vitally important in the process of learning since new knowledge is created through the transformation of experiences [12, 13]. Therefore, the design of pedagogy should aim at helping children associate personal experiences with the learning content.

Insufficient interactivity within the problem scenario: The learning of safety knowledge can be perceived as a kind of problem-based learning because it requires students to implement adequate strategies in order to protect themselves in specific problem scenario. Yet, lecture-based instructions restrict and ignore the importance of 
interactivity when a student engages in problem-solving activities. Conventional safety education is often taught in a teacher-centered classroom rather than studentcentered, which could hinder the exercise of problem-solving activities [14]. Ideally, the curriculum should be organized and presented in an interactive manner that encourages each student to make responses with respect to any changes in problem scenarios. In other words, to understand the applications of safety rules, students are supposed to interact vigorously and critically with problem scenarios rather than just passively receive the knowledge. To this end, multimedia media elements could be applied to the curriculum design to enhance the interactivity in learning and teaching activities.

No instant feedback for effective instructional interventions: Feedback generally refers to any format of responses to students about their behavior or performance. It is nearly impossible for teachers to provide individual, customized feedback to each student's learning results of safety knowledge in a traditional classroom setting. One possible way for teachers to send feedback to students' learning results is through verbal guidance. However, verbal guidance is time-consuming while offering instant feedback is crucial to the teaching of safety knowledge as it helps students to constantly examine their thinking and reasoning process under a given situation. Instant feedback should be designed according to students' actual learning outcome so that follow-up instructional interventions and supports can be implemented. Empirical studies have found that providing instant feedback or prompt during learning is beneficial to students' thinking process $[15,16]$. In the meantime, teachers can monitor students' learning progress by investigating the feedback messages they receive along the way. In addition, instant feedback is also conducive to sustain students' motivation and interest of learning safety knowledge.

Failure to simulate real world situations: Didactic lectures may improve the memorization of declarative knowledge, yet its help is minimal to the understanding of procedural knowledge. In practice, though safety issues are often taught in classroom settings for children; however, some topics are better demonstrated through interactive media such as simulations for safety concerns. For instance, hands-on learning of electricity hazards could involve certain level of risks and danger and henceforth not suitable for children to operate without proper training and assistance from adults. Simulations are often designed to not only replace but also amplify real experiences with a simplified version of real situation. It is immersive in nature and replicate substantial aspects of the real world in a fully interactive fashion [17]. Creating educational simulations to capture the essence of a safety related learning topic would encourage students to safely test out their assumptions through hands-on practices.

In sum, safety related knowledge is critical for children to acquire, however, the conventional teaching practices are not in pace with the current learning needs of safety knowledge for children. The lack of a situated learning context, the disconnections between one's personal experiences and learning content, the insufficient interactivity within the problem scenario, the lack of instant feedback to the student and failure to simulate real world situations - all these are current problems await educators to overcome. 


\subsection{Video games and safety education}

A common and popular approach to make learning more interactive and engaging for children is through the integration of interactive video games. Video games have been integrated into curriculum design for a variety of learning subject in the past. The overarching goal of implementing a game-based curriculum is to transform passive learning of knowledge into active exploration of knowledge because video games provide an intuitive way to guide the student to actively construct knowledge through interacting with game context and characters $[18,19]$. In practice, video games are considered an effective teaching vehicle because of what a game can embody and what students are doing as they play a game [20]. Playing video games consists of two elements: the physical activity of playing a computer game, and the player's meaning-making activities and understanding of the game [21]. In order to make the two elements complement each other, game players need to implement different gaming strategies as a means to analyze, synthesize, and use critical thinking skills to achieve learning goals.

The idea of teaching young children safety knowledge through the process of game playing has been intensively studied by many researchers. In relevant literature, the notion of a game for safety education can be either in the form of an analog game or a digital game depending on the nature of learning. In terms of analog games, researchers have used board games, dice games and even art clips to engage children in learning safety knowledge such as hazards in food, CPR skills and road safety [22]. These studies came to a conclusion that adding a game element into instruction can effectively enhance children's motivation of learning and their active pursuit of safety related knowledge.

In terms of digital games, researchers have experimented the use of a variety of learning technologies to teach safety knowledge. Researchers developed a gamebased virtual world using the Second Life application to deliver safety issues at workplace [23]. Another study created a serious game called Blaze to arouse students' awareness of fire safety issues through video gameplay [24]. A similar design concept was found in [8], in which they built a road safety simulation game for children, where players carry out activities and solve problems that replicate real life situations. Similarly, Li and Tay also encapsulate road safety knowledge into a video game to help drivers retain road traffic knowledge after they have obtained their license [25]. In review of relevant researches, it seems learning technologies that combined education and entertainment would posse certain attributes that can positively enhance one's motivation of learning and learning outcome.

\section{Design and Development}

This AVG app is developed following a clear design process presented in Figure 1. In essence, the design begin with survey stage and then proceed to design and development stage. The survey stage collects opinions not only from the student but also from teachers and parents in order to form a holistic understanding of instructional demands. It is notable that this app is not done in a one-time design work. Instead, the 
final work is done through numerous iterations of experimentations and testing. We keep revising the curriculum content as well as user interface by constantly collecting feedback from the users.

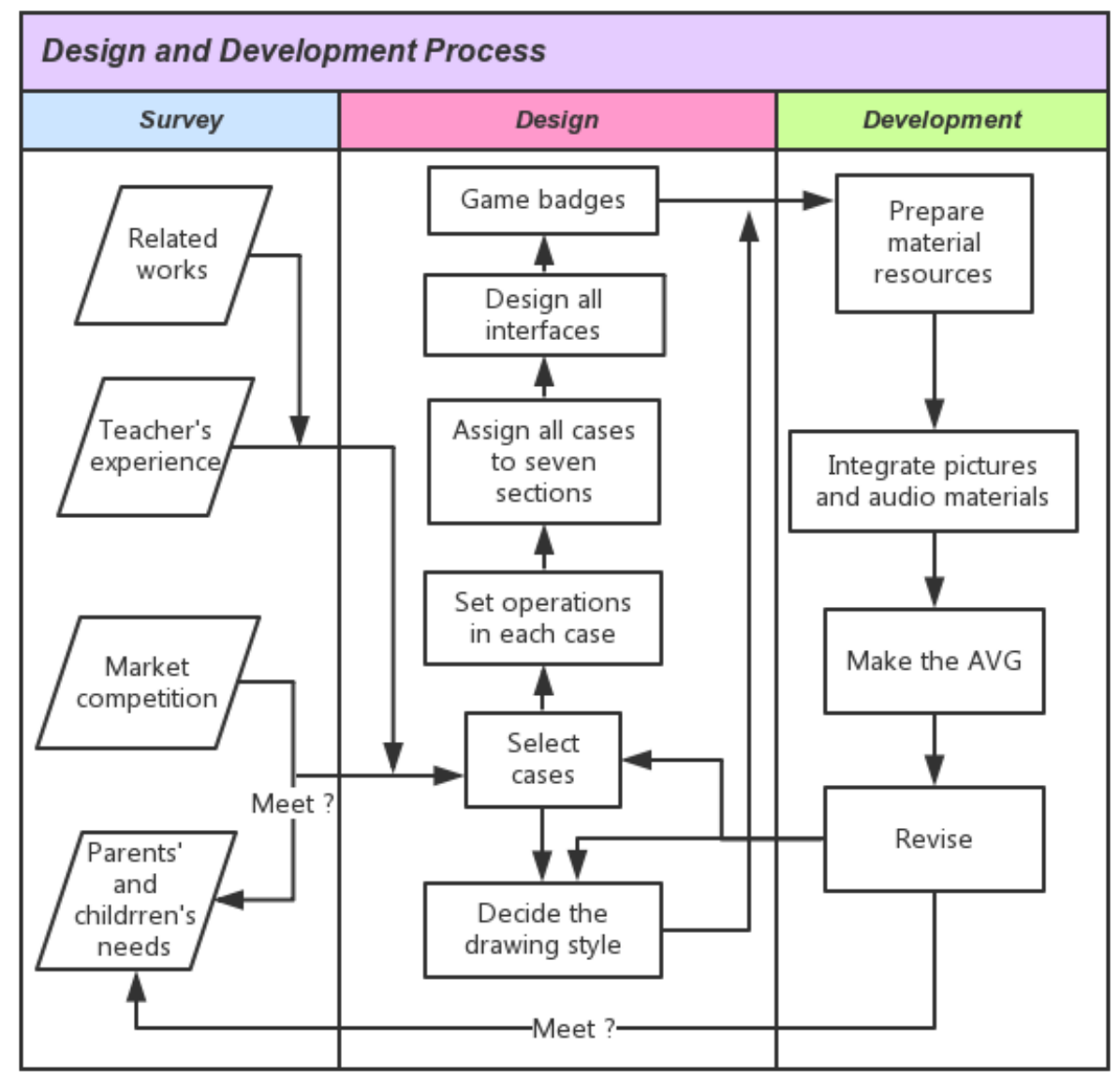

Fig. 1. Process of Design and Development

The goal of this study is to design and develop a scenario-based, adventure video game on a mobile device that can engage children in learning safety knowledge through immersing themselves in the gameplay. The proposed study is intended to answer the following research questions:

- Does playing the AVG app on a mobile device facilitate the learning of safety knowledge?

- What are children and parents' perceptions of the AVG app?

- What are experts' opinions on the design and implementation of the AVG app?

To make it clear, we summarize the theoretical underpinnings and design details of the proposed video game as follows (Please see table 1). 
Table 1. Design and Development of the AVG app

\begin{tabular}{|l|l|l|}
\hline \multicolumn{1}{|c|}{ Components } & \multicolumn{1}{|c|}{ Theoretical foundations } & \multicolumn{1}{c|}{ Design details } \\
\hline Overall structure & Situated learning & $\begin{array}{l}\text { This game contains 7 themes } \\
\text { presented under relevant } \\
\text { problem scenarios }\end{array}$ \\
\hline User interface design & $\begin{array}{l}\text { The cognitive feature and } \\
\text { preference of children aged 6-9: } \\
\text { enjoying lively cartoon figures } \\
\text { but poor in reading }\end{array}$ & $\begin{array}{l}\text { This game presents pictures and } \\
\text { voice to facilitate learning. All } \\
\text { scenes and characters are paint- } \\
\text { ed in 2D. }\end{array}$ \\
\hline Rewards & Motivation of learning & $\begin{array}{l}\text { This game implements a reward } \\
\text { system by using badges and } \\
\text { game characters. The fewer } \\
\text { mistakes a participant makes, } \\
\text { the more stars he/she will get, } \\
\text { and the more characters they } \\
\text { can unlock for the next game. }\end{array}$ \\
\hline Feedback & Principle of timely feedback & $\begin{array}{l}\text { This game provides various } \\
\text { forms of prompts to indicate } \\
\text { children when they do not know } \\
\text { what to do or make a mistake. }\end{array}$ \\
\hline
\end{tabular}

\subsection{Overall structure}

This first-person game allows children to have an experience of real life situations through role-playing. The game provides various case scenarios with security-related problems children might encounter in their daily life.

Following the audiovisual prompts, players are required to manipulate the activities of virtual characters or operate items in order to tackle with safety problems. In other words, the goal for each player is to engage in problem-solving activities by acting out the role within a narrative.

The game contains 7 themes with different problem scenarios while each theme consists of 3 cases. All cases are unique and designed to simulate the situations a child may encounter at different locations in a day (i.e., on the way to school, on campus, on the way home, in a park or by a river). For instance, in one case, players are asked to guide their game character to safely pass through the street by responding to the color of traffic signs correctly.

\subsection{Feedback and reward}

Game Badges: When a new game mission starts, participants will possess five game badges by default. Whenever a mission is done, a new badge will be awarded to the participant. Namely, whenever a mistake is made, one badge will be removed from the scoring board. If all five stars are removed, the game ends. The idea of adding game badges symbolizes not only bragging rights but also a connection with real world situations.

New Game Characters: The AVG app came with two game characters by default. Once a mission is completed, participants can unlock a new game character as a reward to their achievements. The idea of acquiring new characters upon completion is 
to offer participants a sense of affirmation and motivate them to move on to the next mission.

Interactive Feedback: Whenever participants are perplexed by the problem or perform error operations, the AVG app will show them prompts as thinking supports. For instance, highlighting the item as a hint so that the participant knows where to drag or click.

User Interface Design: As the target players are aged between 6 to 9 years old, the app gives prompts mainly by graphics and voice clips. Considering the participant's Chinese literacy skill, there is pinyin notation (the Romanization system for Chinese characters) above every character that matches. All interfaces are designed according to the following principles: simple to facilitate, attractive, authentic and intuitive. In general, the app consists of three types of interfaces:

- Main Interface: The main interface is simple and straightforward (Please see Figure 2) that has two functional buttons (Start and Settings) for participants to start with.

- Setting Interface: In this interface (Please see Figure 3), participants can configure their game character and control background music and voice prompt settings. The icon of the character can be modified through touching the small triangles on both sides. The stars possessed by children are below the name.

- Game Interface: The function of the transition interface is to demonstrate the background image associated with each case to immerse children in the narratives. For instance, as Figure 4 shows, participants are supposed to find something to eat from several food choices on the table. After touching the red bag, participants can obtain an enlargement picture with more details and information such as the expiration dates.

The three function icons are in the top right/left corner. Each participant should make judgments by manipulating the buttons (i.e., click, drag, and shake) according to the case scenarios. For instance, when the traffic light is red in Figure 5, participants should wait patiently and keep out of the road until the light turns green. When the light turns green, children are supposed to walk through the road orderly and quickly (voice prompt), which requires an uninterruptible drag operation of the character. After safely pass over the road, there are other challenges await each participant. For instance, when getting close to the highlighted manhole cover in Figure 6, the participant has to think of a way to avoid falling into it. Though a possible solution is to drag the cover to its proper situation, it is too difficult and dangerous for children to do this without additional help, so the suggested solution in this case is taking a detour to stay away from the manhole. 


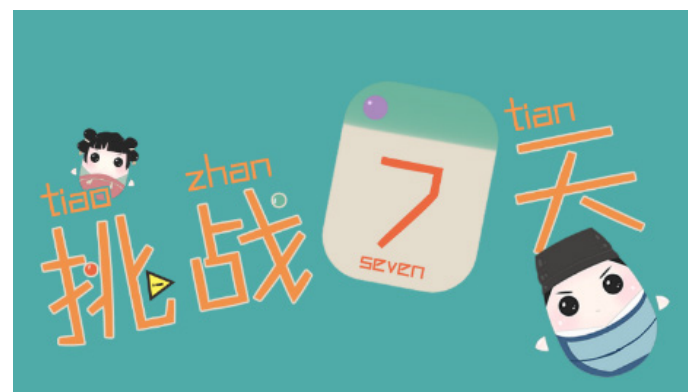

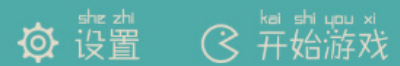

Fig. 2. AVG app Main Interface.

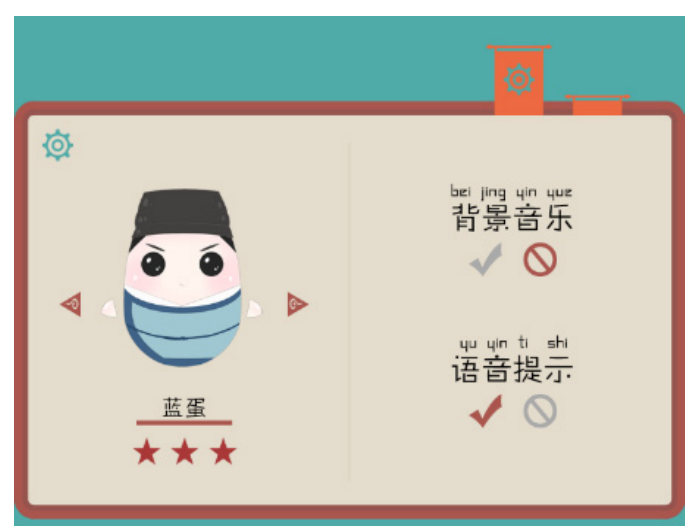

Fig. 3. Function Setting Interface

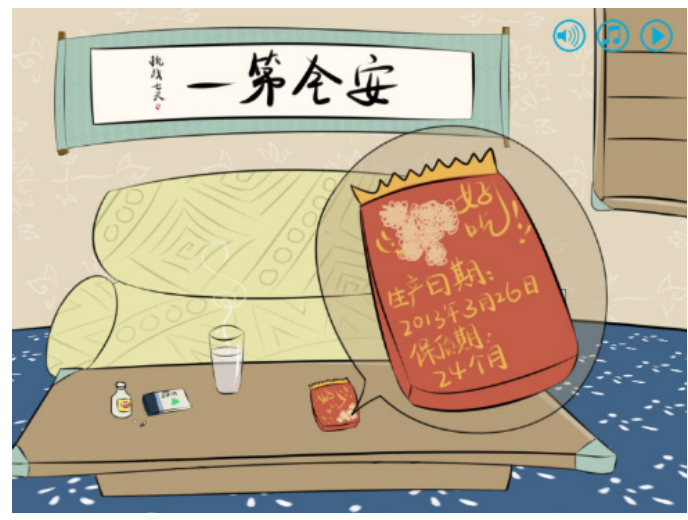

Fig. 4. Food Safety Scenario 

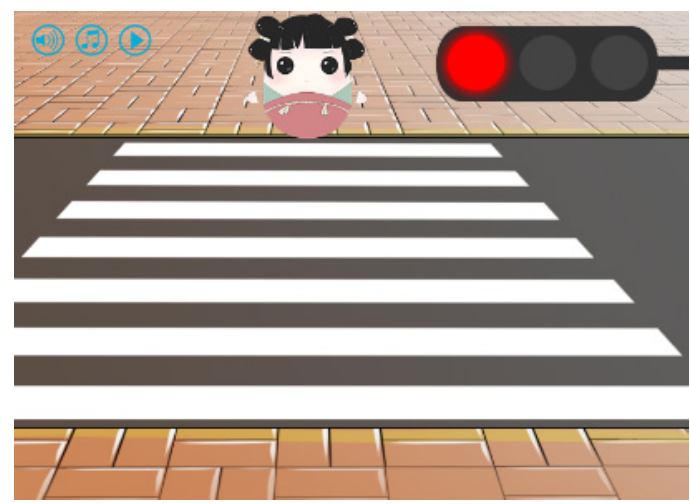

Fig. 5. Traffic Light Scenario

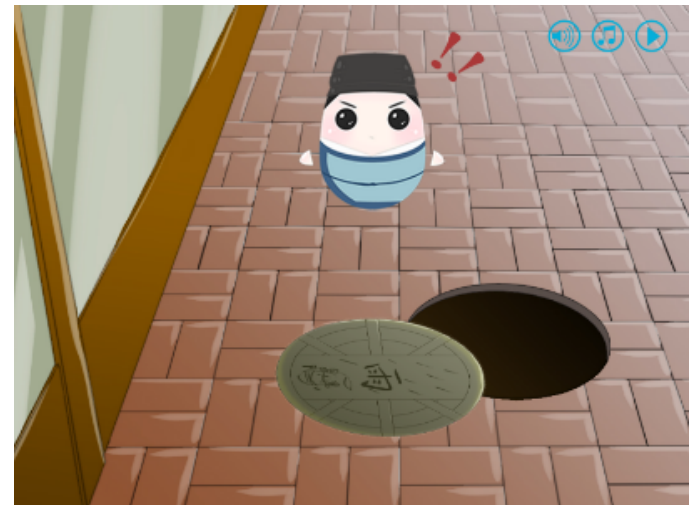

Fig. 6. Road Safety Scenario

\section{Method}

\subsection{Participants}

Given the appropriate age of game players for the AVG app, we selected a bilingual kindergarten located in the city of Beijing as the primary subject of this study. A total of 11 children ( 8 girls and 3 boys) were randomly selected and recruited to join the video gameplay treatment. The average age of participants is 6.5 years old. Prior to the start of the treatment, all participants alleged that they have previous exposure to video gameplay experiences on mobile devices at home.

\subsection{Research settings}

The experiment was conducted in a quiet classroom in the morning where participants can better focus on the learning content without being disturbed. All 11 partici- 
pants took turns to play the AVG app one by one. The instructors worked with one participant at a time to explain the treatment procedure and rules of the adventure game. Once the explanation was done, each participant was given an 8-inch handheld tablet to start playing the AVG app.

\subsection{Procedure}

The treatment session began with video gameplay, followed by in-depth interviews. All participants were given a cover story, in which they encountered a time traveller who travelled from prehistoric days to the present time and have very limited knowledge about surviving in this modern world. Their task was to teach the time traveller safety relevant knowledge in different aspects of life in order to survive. Therefore, all participants were required to assist this time traveller to deal with life problems through playing the AVG app. Once all learning tasks were completed, an interview was conducted to understand each participant's perceptions of the game. Participants will be interviewed about their emotion, interests and flow during their playing as soon as they were done playing the game. The in-depth interview followed a protocol of open-ended questions. Sample questions were as follows:

- What are the most difficult and challenging events during the gameplay? Why?

- What cause you to make a mistake in the game?

- What is your overall impression about this video game?

- What are your likes and dislikes about this video game?

- Would you like to try a similar genre of game in the future?

\subsection{Materials}

All of the scenes and icons for this game were painted in 2D using the Adobe Photoshop software. The core of the AVG app was created with the GameSalad programming application. For each participant, there were a total of 7 learning themes to finish up, including topics such as: (1) road safety, (2) food safety, (3) electricity safety, (4) personal safety, (5) outdoor safety, (6) interpersonal safety and (7) emergency safety. Each theme was presented in relevant problem scenarios (see Table 2).

Table 2. Themes overview

\begin{tabular}{|l|l|}
\hline \multicolumn{1}{|c|}{ Themes } & \multicolumn{1}{c|}{ Problem Scenarios } \\
\hline Road safety & Cross over the road \\
\hline Food safety & Safety of food \\
\hline Electricity safety & Correct use of electricity \\
\hline Personal safety & Safety issues on the street \\
\hline Outdoor safety & Safety issues by the river \\
\hline Interpersonal safety & Approached by strangers \\
\hline Emergency safety & CPR practices \\
\hline
\end{tabular}




\subsection{Measures}

This study implemented a formative assessment that took place throughout the video gameplay process to inform researchers participants' learning outcome. A number of measures were implemented in this study in order to investigate the effectiveness of the proposed video game. First, descriptive statistics were conducted on participants' learning outcomes, including the average time spent on completing the game, the recall percentage for each learning theme and the average correct percentage for each learning theme. Second, in-depth interviews and video analysis were used to assess the learning outcomes. Participants' operations and navigations on the screen were videotaped by a screen capture application. Later, we coded and analyzed the screen capture files in order to understand participants' operational preference, selection tendency and task achievements when engaging in the game. Lastly, 3 professors specializing in video game design, learning and child psychology were invited to give feedback on the game design. Figure 7 clearly illustrated how comments and feedback from different sources were collected to inform and improve the design of the AVG app.

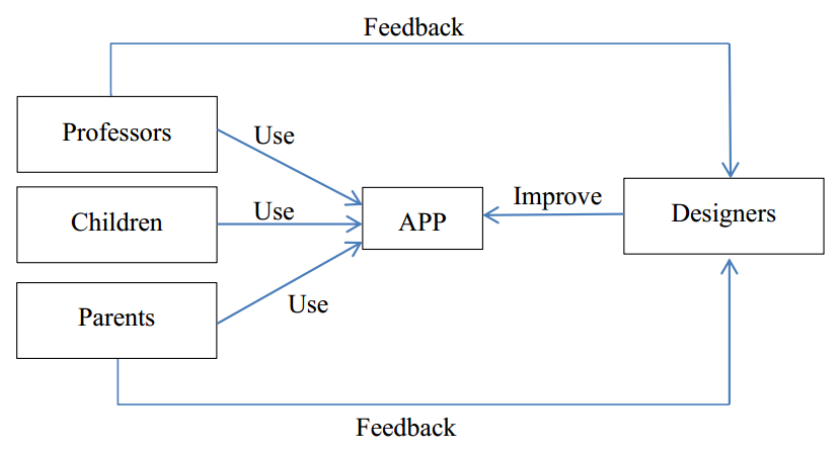

Fig. 7. The Feedback loop

\section{$5 \quad$ Result and Analysis}

The following analysis on data was intended to answer the three research questions mentioned in previous section, followed by discussions, research limitations and future research directions.

\subsection{Does playing the AVG app facilitate the learning of safety education?}

Though this study recruited a small number of participants, the interview results indicated that all 11 children regarded the AVG app as an interactive, intriguing and engaging video game to play with. Meanwhile, the perceived level of difficulty of this game was low across all participants. Data analysis showed that the average time for participants to complete the 7 learning themes is roughly 6 minutes. In general, partic- 
ipants had fun with the nature of the task by helping a time traveller to survive and get converted into modern life. It seemed the cover story itself enhanced participants' motivation of learning at the first place. When asking participants to recall what they have learned in the AVG app, each participant could recall an average of 5 themes. Besides, it was found that participants retained better memory for learning themes such as electricity safety $(81.8 \%)$, outdoor safety $(72.7 \%)$, emergency safety $(72.7 \%)$ and road safety $(72.7 \%)$. Interestingly, those themes that they could quickly recall happened to be the ones they received relatively higher error rate. The data analysis indicated that the top two learning themes participants struggled with were food safety and electricity safety. An overview of the result can be seen in Table 3 .

Table 3. Data analysis overview

\begin{tabular}{|c|l|c|c|c|}
\hline Themes & \multicolumn{1}{|c|}{$\begin{array}{c}\text { Problem } \\
\text { Scenarios }\end{array}$} & $\begin{array}{c}\text { Perceived } \\
\text { difficulty } \\
\text { (percentage) }\end{array}$ & $\begin{array}{c}\text { Recall } \\
\text { rate } \\
\text { (percentage) }\end{array}$ & $\begin{array}{c}\text { Error } \\
\text { rate } \\
\text { (percentage) }\end{array}$ \\
\hline Road safety & Road-crossing & $0 \%$ & $72.7 \%$ & $27.3 \%$ \\
\hline Food safety & Expiration date check & $27.3 \%$ & $36.4 \%$ & $100 \%$ \\
\hline Electricity safety & Electric shock & $45.5 \%$ & $81.8 \%$ & $72.7 \%$ \\
\hline Personal safety & Everyday life & $9.1 \%$ & $54.5 \%$ & $27.3 \%$ \\
\hline Outdoor safety & Water security & $0 \%$ & $72.7 \%$ & $9.1 \%$ \\
\hline Interpersonal safety & Threat of strangers & $0 \%$ & $54.5 \%$ & $9.1 \%$ \\
\hline Emergency safety & CPR practices & $9.1 \%$ & $72.7 \%$ & $45.5 \%$ \\
\hline
\end{tabular}

\subsection{What are participants' perceptions about the AVG app?}

Follow-up in-depth interviews helped us better understand the reasons behind these numbers. For food safety, it was found that most participants were unable to figure out the expiration date of food products. In china, most food products do not have expiration date printed on them. Instead, they use production date (or manufacturer date). Therefore, participants must look for period after opening (PAO) information in order to calculate the expiration date on their own. For instance, 6 months means that the product can be used for six months after it has opened. It seemed all participants struggled with expiration date of food so that the error rate was 1 . For electricity safety, both the data analysis and interviews guided us to recognize that participants at the age of 6 did not possess enough knowledge about the hazards associated with electricity, which was vital to the protection of their everyday life. In the meantime, there were two findings about participants' learning results that were worth investigating. One was in the theme of road safety in which many participants tended to believe that pedestrians are safe to walk across the street even when a traffic light turns into yellow. The other learning issue was about the memorization of emergency phone number in China. During the interviews, we found that half of the participants were unaware of the number 120 is in fact created for first-aid assistances such as calling an ambulance. 


\subsection{What are parents' perceptions about the AVG app?}

We interviewed the parents of each participant in order to understand their impressions about this AVG app. Surprisingly, the interview results indicated that most parents held pretty negative attitudes toward the idea of using video games as a teaching tool. They doubted the suitability of integrating video games into any academic subjects. On the contrary, for safety related issues, they tended to believe that a pragmatic solution to enhance a child's personal safety is through tracking and monitoring his/her physical location with technology devices. These parents asserted that even though a child was aware of the importance of safety issues in life, he/she might not be capable of handling an abrupt problem in a proper manner. After all, they trusted a real human teacher more than what a video game could deliver.

\subsection{What are experts' opinions on the design and implementation of the AVG app?}

Three experts in the field of education and technology were invited to provide their insightful comments on the design and implementation of the AVG app. All three experts' feedback on the AVG app was quiet positive and constructive that can be summarized as two parts - the advantage of the AVG app and future development suggestions. The main advantage of the AVG app lay in its solid design rationale and diversity in learning themes. After thoroughly reviewed and played the AVG app in person, these experts unanimously agreed that all problem scenarios presented in this game were closely aligned with current safety learning issues that a child may encounter everyday life. The interface design and game flow was friendly and appropriate for game players who were aged from 6 to 9 .

Speaking of future suggestions, these experts' opinions can be categorized as three dimensions: the goals of this AVG app, the design of curriculum content and the design of feedback message. When designing an app that aimed at teaching children safety education, it was suggested that researchers should first ask themselves what are the goals of this app. In practice, a safety education game can be implemented either as a multimedia tool to facilitate children's learning, as a monitoring tool to identify children's learning insufficiencies, or an assessment tool to evaluate children's learning outcome. However, the distinction of learning goals for this study seemed somewhat blurring to those experts. It is critical to clarify the purposes of the video game as different learning goals would greatly influence the pragmatic design principles, user interface as well as measurement criteria of the app. Next, the design of curriculum content should be consistent in terms of level of difficulty. In this study, the curriculum on food safety was a relatively more challenging learning theme as compared to others. The participant might not possess the math skills required to calculate the exact expiration date by referring to the production date printed on the bag. The last suggestion surrounds the design of feedback message in the AVG app. The feedback message in the current AVG app was not enough to offer adequate supports. Moreover, the feedback was presented mostly as printed text on the screen that lacks interactivity. It was suggested that more audiovisual prompts should be 
implemented in this game not only as navigational guide but also scaffolds to facilitate deeper learning and thinking activities.

\section{Discussions and Results}

The aim of this study was twofold. On the one hand, we investigated the current issues and deficiencies of teaching children's safety related knowledge. On the other hand, we proposed a solution to deal with the aforementioned problems by designing an adventure video game (AVG) to engage children in learning safety knowledge. We will first discuss the result of this study followed by our reflections of thinking and relevant educational implications.

The proposed AVG app was designed and implemented based on the learning and teaching problems identified in the previous section. The AVG app's design rationale was in fact a response to those teaching deficiencies. We assumed that the nature of video games and digital media enhance the interactivity, customization, feedback message and audiovisual effect during the instruction. The data analysis results revealed that most participants were very satisfied with this learning by playing experience. They were quiet positive about exercising their safety knowledge with an adventure-based video game on mobile devices. These findings are consistent with most game-based learning experiments as children are naturally more motivated to learn a new subject with video games than with static, written materials [19, 26, 27, 30, 32]. We then delved deeper to take a look at participants' error rate for each learning theme. It was noticeable that everyone failed in the food safety theme. Interestingly, the failure was not due to insufficient training in food safety practices. Instead, it was a simple mathematical problem that perplexed the participant. For us, this is an important implication for the instructional design practice of safety education curriculum. This inspired us to think about the relationship between a child's mathematical skills and the learning of safety knowledge - an issue that hasn't been widely mentioned or discussed in the previous literature. Could one's mathematical skills influence his/her abilities to solve a safety problem? Could one's mathematical skills become an indicator of his/her ability to apply safety knowledge to real world problems? Though mathematical skills are not directly related to the learning of safety knowledge, it seems basic number operations skills are required when learning safety related knowledge. For instance, addition operation skill is required to correctly figure out the expiration date for food products, especially for children in China. Yet, food safety is not the only safety theme that involves mathematics. Other topics such as electricity safety also required one's mathematical literacy skills in order to calculate the maximum load for a fuse to avoid problems such as fuse blown out. In essences, the design of safety education curriculum should take participants' mathematical literacy skills into consideration. It would be worth examining the interrelationship between a child's safety knowledge and mathematical skills when solving a problem.

Findings from the road safety theme reminded us the importance of keeping parents in the loop when teaching children safety issues. It was reported that most participants misunderstood the function of the yellow traffic light when crossing a road. 
Surprisingly, they thought the yellow light meant a to go sign, which was of no difference to the green light. One possible explanation is they simply imitated the behavior of their parents. Since children at the age of 6 can not pass a road by themselves without the accompany of an adult, their understanding and knowledge about road safety and traffic light was derived directly from their parents. Parents might see traffic light as a reference rather than a strict rule to follow, and their behaviors and logic in thinking was naturally passed down to the next generation. Therefore, it seemed to us that safety education indeed requires parents' involvement and cooperation because children confront safety related issues not only in school but also at home. This is consistent with what we found in the literature [5,31]. In this study, parents' involvement can be discussed from two dimensions. The first dimension was parents' roles in guiding children to uncover safety rules by using themselves as live curriculum. Parents can offer active, in-time, direct feedback to their child's behaviors, thereby play a significant role in co-constructing safety knowledge with their children. Therefore, the learning of safety knowledge for children is not completely learner-centered. It requires the facilitation of both parents and teachers. The second dimension was parents' attitude toward the use of video games in the classroom. It was totally understandable that parents tended to suspect the boundary between the value of learning and video games, and worry about possible negative influences on learning caused by the presence of video games. One possible solution is to invite parents to brainstorm curriculum ideas with teachers when designing a video game-based learning tool. Besides, future development of the AVG app might want to include parents as a new game character in the game script so that both children and their parents can play the game together.

Another issue that came to our attention was the relatively high error rate for learning themes such as electricity safety and emergency safety. The high tendency for mistakes in learning was in fact caused by the different types of knowledge and cognitive skills required for solving a problem. In general, there are two main types of knowledge - declarative knowledge and procedural knowledge. Here, both the two themes require the use of procedural knowledge more than on declarative knowledge when solving a problem. Unlike declarative knowledge that is bounded in nature, procedural knowledge referred to a type of knowledge that is formed by undertaking a task or hands-on practices [28]. For instance, the skills required to successfully perform a CPR is considered as a procedural knowledge. The formation of procedural knowledge took constant practice and observations henceforth added another layer of difficulty that results in increased error rate. However, we are not trying to come to a hasty conclusion that procedural knowledge related safety issues would result in higher error rate for children than declarative knowledge. In this study, for instance, the interpersonal safety theme in which participants were being approached by a stranger would require the exercise of procedural knowledge more than that of declarative knowledge. However, the reported error rate for this theme was only $9 \%$. Thus, the educational implication here is to allow us to firstly identify the type of knowledge and relevant cognitive skills when designing safety learning related curriculum. Once the type of knowledge is clearly defined and identified, it becomes easier for re- 
searchers to further understand the causal relationship underlying the results, so that adequate instructional supports can be provided.

\section{$7 \quad$ Limitations}

Although this is a well-designed study that collected valuable data through rigorous design and implementation process, there are a number of limitations that are worthy of consideration as the results and implications are considered. One limitation is participants' prior knowledge about different safety learning issues. Since the learning of safety knowledge could happen both in school and at home, it is difficult to control participants' exposure to different safety education issues before the treatment. The other limitation is the number of participants for this study. Considering on-site human resource and parents' attitude toward video games, we only recruited 11 children as participants of this study. The third limitation is the length of time participants exposed to the AVG app. The average amount of time each participant spent on playing the app could be too short to see any differences in learning outcomes. Lastly, the final limitation is the graphical design of user interface which only implements 2D images that might not be as effective as 3D images in terms of fostering one's spatial thinking skills in problem-solving activities [29].

The study of a child's safety education should not be confined to school settings. In addition to the aforementioned safety learning themes, future studies might want to expand the scope of research by investigating different learning scenarios. First, there are emerging safety issues a child may encounter when stepping into in the cyber worlds. It has become an irresistible trend that children expose themselves to technology devices and applications at an early age. The emergence of social media also enables new modes of communication that appears to be enticing to children. However, online social media creates new issues for children. For instance, cyber bullying is one of the critical concerns that a child has to learn to deal with. It will be challenging yet meaningful to transform online safety issues into video games. Second, the AVG app is developed for a single player, meaning the influence from peers in the process of constructing safety knowledge remain unexplored. Future studies may create a multi-player video game that investigates how children work as a group to cope with safety related problems.

\section{$8 \quad$ References}

[1] Waters, S., Baker, S., \& Bruce, K. (2012). National Practices for Early Childhood Road Safety Education. Perth, Australia: Edith Cowan University, Child Health Promotion Research Centre.

[2] Bas, M., Yüksel, M., Çavuoofl. U. T. (2007). Difficulties and barriers for the implementing of HACCP and food safety systems in food businesses in Turkey, Food Control $18,124-130$.

[3] Zeedyk, M., Wallace, L., Carcary, W., Jones, K. \& Larter,K. (2001). Children and road safety: increasing knowledge does not improve behaviour. British Journal of Educational Psychology, 71, 573-594. https://doi.org/10.1348/000709901158686 
[4] Liu. Y., Gu, D., Qing, J., Zhang, Y., Luo, W., Wang, F. (2008). A Survey on the Implementation of Safety Education by Primary and Secondary School Teachers in Beijing. Teacher Education Research, 1(26), 69-73.

[5] Thomson, J.A., Ampofo-Boateng, K., Lee, D.N., Grieve, R., Pitcairn, T.K. \& Demetre, J.D. (1998). The effectiveness of parents in promoting the development of road crossing skills in young children. British Journal of Educational Psychology, 68, 475-491. https://doi.org/10.1111/j.2044-8279.1998.tb01306.x

[6] Dickey, M. D. (2006). Game Design Narrative for Learning: Appropriating Adventure Game Design Narrative Devices and Techniques for the Design of Interactive Learning Environments. Educational Technology Research and Development, 6(3), 245-263. https://doi.org/10.1007/s11423-006-8806-y

[7] Price, J., Murnan, J., Thompson, A., Dake, J., \& Telljohann, S. (2005). Elementary school teachers' involvement in firearm safety education. Journal of School Health, 75(3), 105111. https://doi.org/10.1111/j.1746-1561.2005.tb06650.x

[8] Ariffin, M. M., Downe, A. G., \& Aziz, I. A. A. (2010). Developing a Simulation Game to Facilitate theAcquisition and Transfer of Road Safety Knowledge. Paper presented at the Information Technology (ITSim) 2010. doi: http://10.1109/ITSIM.2010.5561536. https://doi.org/10.1109/ITSIM.2010.5561536

[9] Lave, J., \& Wenger, E. (1990). Situated Learning: Legitimate Periperal Participation. Cambridge, UK: Cambridge University Press.

[10] Kolb, D. A. (1993). The process of experiential learning. In M. Thorpe, R. Edwards, \& A. Hanson (Eds.), Culture and processes of adult learning. New York: Routledge.

[11] Lawler, R. W. (1985). Computer experience and cognitive development: A child's learning in a computer culture. New York: Halsted Press.

[12] Hanson, R. E. (2000). The role of experience in learning: giving meaning and authenticity to the learning process in schools. Journal of Technology Education, 11(2), 23-32. https://doi.org/10.21061/jte.v11i2.a.2

[13] Kolb, D. A. (1984). Experiential learning: experience as the source of learning and development. Englewood Cliffs: Prentice Hall.

[14] Barrett, T. (2010). The problem-based learning process as finding and being in flow. Innovations in Education and Teaching International. 47 (2), 165-174. https://doi.org/10.1080/14703291003718901

[15] Li, L., Liu, X. \& Steckelberg, A. L. (2010). Assessor or assessee: how student learning improves by giving and receiving peer feedback. British Journal of Educational Technology, 41, 525-536. https://doi.org/10.1111/j.1467-8535.2009.00968.x

[16] Narciss, S. \& Huth, K. (2006). Fostering achievement and motivation with bug-related tutoring feedback in a computer-based training for written subtraction. Learning and Instruction, 16(4), 310-322. https://doi.org/10.1016/j.learninstruc.2006.07.003

[17] Lateef, F. (2010). Simulation-based learning: Just like the real thing. Journal of Emergency Trauma Shock, 3(4), 348-352. https://doi.org/10.4103/0974-2700.70743

[18] Amory, A., Naicker, K., Vincent, J., \& Adams, C. (1999). The use of computer games as an educational tool: identification of appropriate game types and game elements. British Journal of Educational Technology, 30(4), 311-321. https://doi.org/10.1111/1467$\underline{8535.00121}$

[19] Gee, J. P. (2003). What video games have to teach us about learning and literacy. New York: PalgraveMacMillan.

[20] Eck, R. V. (2006). Digital game-based learning. Educause Review, 41, 17-30.

[21] Rambusch, J. (2006) The Embodied and Situated Nature of Computer Game Play. Workshop on the cognitive science of games and game play. Vancouver, Canada.

[22] Oyarzabal, O. A. (2015). Using Dice Games to Teach Hazards, Risk, and Outcomes in HACCP Classes. Journal of Extension, 53(4), Article 4TOT7. 
[23] Viegas, S. C., \& Santos, R. P. (2012). Second Life: A New Approach In Professional Education In The Study Of Work Safety. IEEE Latin America Transactions, 10(1), 14201424. https://doi.org/10.1109/TLA.2012.6142495

[24] DeChamplain, A., Rosendale, E., McCabe, I., Stephan, M., Cole, V., \& Kapralos, B. (2012). Blaze: A serious game for improving household fire safety awareness. Paper presented at the 2012 IEEE International Games Innovation Conference (IGIC). Doi: 10.1109/IGIC.2012.6329839. https://doi.org/10.1109/IGIC.2012.6329839

[25] Li, Q., \& Tay, R. (2014). Improving drivers' knowledge of road rules using video games. Accident Analysis \& Prevention, 65, 8-10. https://doi.org/10.1016/j.aap.2013.12.003

[26] Prensky, M. (2003). Digital game-based learning. ACM Computers in Entertainment, 1(1), 1-4. https://doi.org/10.1145/950566.950596

[27] Ritterfeld, U., \&Weber, R. (2006). Video games for entertainment and education. In P. Vorderer, \& J. Bryant (Eds.), Playing video games. Motives, responses, and consequences (pp. 399-413). Mahwah, NJ: Lawrence Erlbaum Associates.

[28] Stadler, M. A. (1989). On Learning Complex Procedural Knowledge. Journal Of Experimental Psychology: Learning, Memory, and Cognition, 15(6), 1061-1069. https://doi.org/10.1037/0278-7393.15.6.1061

[29] Clements, D. H., \& Battista, M. T. (1992). Geometry and Spatial Reasoning. In Handbook of Research on Mathematics Teaching and Learning, edited by Grouws, D. A. (pp. 420464). New York: Macmillan Publishing Company.

[30] Brom, C., Preuss, M., Klement, D. (2011). Are Educational Computer Micro-Games Engaging and Effective for Knowledge Acquisition At High-Schools? A Quasi-experimental Study. Computers \& Education, 57(3), 1971-1988. https://doi.org/10.1016/j.comp edu.2011.04.007

[31] Lin, K.Y., Son, J.W., \&Rojas, E. M. (2011). A pilot study of a 3D game environment for construction safety education. Journal of Information Technology in Construction. 16, 6984.

[32] Tsung-Yen Chuang, Wei-Fan Chen. Effect of Computer-Based Video Games on Children: An Experimental Study[J]. Journal of Educational Technology \& Society, 2009, 12(2): $1-10$.

\section{Authors}

Feng-Kuang Chiang is a distinguished professor in the Department of Educational Technology at Shanghai Normal University, China. His research focused on STEM education, learning space and integration of information technology and curriculum.

Chun-Hao Chang is a postdoctoral researcher in the Department of Computer Sciences and Electronic Engineering at National Taiwan Normal University, Taiwan.

Danni Hu is a graduate student in the Department of Educational Technology at Beijing Normal University, China.

Geran Zhang is a graduate student in the Department of Educational Technology at Beijing Normal University, China.

Ying Liu is a graduate student in the Department of Educational Technology at Beijing Normal University, China.

Article submitted 24 July 2018. Resubmitted 04 January 2019. Final acceptance 10 January 2019. Final version published as submitted by the author. 